\title{
Upregulation of ERCCI and DPD expressions after oxaliplatin- based first-line chemotherapy for metastatic colorectal cancer
}

\author{
H Baba*,', M Watanabe', H Okabe', Y Miyamoto', Y Sakamoto', Y Baba', M Iwatsuki', A Chikamoto' and \\ T Beppu'
}

'Department of Gastroenterological Surgery, Graduate School of Medical Science, Kumamoto University, I-I-I, Honjo, Kumamoto, 860-8556, Japan

BACKGROUND: The updated randomised phase 2/3 FIRIS study demonstrated the noninferiority of IRIS (irinotecan and S-I) to FOLFIRI (irinotecan, folinic acid, and 5-FU) for metastatic colorectal cancer. Meanwhile, in the subset analysis including patients who previously have undergone oxaliplatin-containing chemotherapy, the IRIS group showed longer survival than the FOLFIRI group. However, the molecular mechanism underlying this result is still unknown.

METHODS: The National Cancer Institute 60 (NCI60) cell line panel data were utilised to build the hypothesis. A total of 45 irinotecan-naive metastatic colorectal cancer patients who had undergone hepatic resection were included for the validation study. The mRNA expressions of excision repair cross-complementing group I (ERCCI), dihydropyrimidine dehydrogenase (DPD), and topoisomerase-I (TOPI) were evaluated by quantitative RT-PCR. The expressions of ERCCI and DPD were also evaluated by immunohistochemistry.

RESULTS: Sensitivity to oxaliplatin in 60 cell lines was significantly correlated with that of 5-FU. Resistant cells to oxaliplatin showed significantly higher ERCCI and DPD expression than sensitive cells. In validation study, ERCCI and DPD but not TOPI expressions in cancer cells were significantly higher in FOLFOX (oxaliplatin, folinic acid, and 5-FU)-treated patients $(N=24)$ than nontreated patients $(\mathrm{N}=2 \mathrm{I})$. The ERCCI and DPD protein expressions were also significantly higher in FOLFOX-treated patients.

CONCLUSION: The ERCCI and DPD expression levels at both mRNA and protein levels were significantly higher in patients with oxaliplatin as a first-line chemotherapy than those without oxaliplatin. The IRIS regimens with the DPD inhibitory fluoropyrimidine may show superior activity against DPD-high tumours (e.g., tumours treated with oxaliplatin) compared with FOLFIRI.

British Journal of Cancer (2012) I 07, 1950-1955. doi:I0.1038/bjc.20I2.502 www.bjcancer.com

Published online 20 November 2012

(c) 2012 Cancer Research UK

Keywords: DPD; ERCCI; metastatic colorectal cancer; National Cancer Institute; oxaliplatin

The combination of fluorouracil (5-FU) and folinic acid with either oxaliplatin (FOLFOX-4 and FOLFOX-6 regimens) or irinotecan (FOLFIRI and AIO regimens) has been established as the standard first-line chemotherapy for metastatic colorectal cancer (O'Neil and Goldberg, 2008). Second-line therapy for patients whose disease progresses or recurs has been investigated in several clinical studies (Cunningham et al, 1998; Rougier et al, 1998, 2002; Tournigand et al, 2004). Patients who are initially treated with an oxaliplatin-based regimen tend to be offered an irinotecan-based regimen as secondline therapy and vice versa. However, the basic rationale for a sequential treatment strategy has been poorly studied.

An orally administered 5-FU pro-drug, S-1, is approved for the treatment of gastric cancer, colorectal cancer, breast cancer, head and neck cancer, non-small cell lung cancer, pancreatic cancer, and hepato biliary cancer in Japan, and for gastric cancer in Europe. S-1 consists of tegafur, a pro-drug of 5-FU, 5-chloro-2,4dihydroxypyridine (CDHP), a dihydropyrimidine dehydrogenase $(D P D)$ inhibitor maintaining the serum concentration of 5-FU, and potassium oxonate, an inhibitor of orotate phosphoribosyl transferase that reduces gastrointestinal toxicities.

*Correspondence: Dr H Baba; E-mail: hdobaba@kumamoto-u.ac.jp Received 13 June 2012; revised 8 October 2012; accepted 17 October 2012; published online 20 November 2012
We previously reported the updated results of the randomised phase 2/3 FIRIS study of 426 patients, which reconfirmed the noninferiority of IRIS (irinotecan/S-1) to FOLFIRI using progression-free survival (PFS) as the primary end point (Muro et al, 2010; Baba et al, 2011). Furthermore, we reported the pre-planned subset analysis that revealed that the median overall survival (OS) of the IRIS group in patients who previously underwent oxaliplatincontaining chemotherapy was significantly longer than that of the FOLFIRI group (adjusted HR $=0.755 ; 95 \% \mathrm{CI}=0.580-0.987$ ) (Baba et al, 2011). Regarding this intriguing finding, Muro et al (2010) have speculated that S-1 might have some salvage effects in patients who previously received FOLFOX, containing oxaliplatin with bolus and infusional 5-FU. However, the mechanism underlying this interaction between the presence or absence of oxaliplatin and therapeutic effects in the FIRIS study remains unclear. The current retrospective study therefore investigated the molecular mechanisms for the superiority of IRIS to FOLFIRI in patients previously treated with oxaliplatin-based chemotherapy.

\section{MATERIALS AND METHODS}

\section{NCI60 cell line data}

The National Cancer Institute (NCI) database (http://dtp.nci.nih. gov) containing data from $60 \mathrm{NCI} 60$ cell lines was used as the 
source of cytotoxicity data for oxaliplatin (NSC266046), 5-FU (NSC19893), and DNA copy number. The $\mathrm{GI}_{50}$, which is the concentration required to inhibit growth by $50 \%$, was used as a parameter for cytotoxity. The DNA microarray data for gene expression were downloaded from the Genomics and Bioinformatics group website (http://discover.nci.nih.gov/). Downloaded data were processed and loaded into GeneSpring software, version 7.3 (Agilent Technologies, Santa Clara, CA, USA). Correlations were calculated using Student's $t$-tests with JMP8.0 software (SAS Institute, Tokyo, Japan).

\section{Patient characteristics}

Irinotecan-naive metastatic colorectal cancer patients, with Eastern Cooperative Oncology Group performance status (ECOG PS) 0-1, adequate organ function, and resectable liver metastases were enroled in the study. Blocks from resected tumour specimens of liver metastatic lesions were available from 24 patients who preoperatively received the FOLFOX regimen, and 21 with no prior oxaliplatin-containing chemotherapy. All patients underwent hepatic resection for colorectal liver metastasis in the Department of Gastroenterological Surgery, Kumamoto University. The study was carried out in accordance with the Declaration of Helsinki and Good Clinical Practice Guidelines. Written informed consent was obtained from all patients participating in the study. Approval of the protocol was obtained from an Independent Ethics Committee or the Institutional Review Board.

\section{Microdissection}

Representative haematoxylin and eosin-stained slides of formalinfixed, paraffin-embedded (FFPE) blocks were reviewed by a pathologist to estimate tumour load per sample. Section slides of $10-\mu \mathrm{m}$ thickness were then stained with nuclear fast red (SigmaAldrich, St Louis, MO, USA) for manual microdissection. Malignant cells were selected under microscope magnification of $\times 5$ to $\times 10$ and dissected from the slide using a scalpel as described previously (Ceppi et al, 2006).

\section{Isolation of RNA and cDNA synthesis}

RNA isolation from tumour tissue isolated by manual microdissection and cDNA preparation steps were accomplished as described previously (Kuramochi et al, 2006), with a slight modification in the extraction step using RNeasy Mini Elute spincolumns (Qiagen, Chatsworth, GA, USA).

\section{Quantitative real-time PCR}

Gene expression levels of excision repair cross-complementing group 1 (ERCC1), DPD, and topoisomerase-1 (TOP1) were determined using TaqMan real-time PCR (Life Technologies, Foster City, CA, USA) as described previously (Kuramochi et al, 2006). $\beta$-Actin was used $(A C T B)$ as an endogenous reference gene. All genes were run on all samples in triplicate. The detection of amplified cDNA results in a cycle threshold $(\mathrm{Ct})$ value, which is inversely proportional to the amount of cDNA. Universal Mix RNAs (Stratagene, La Jolla, CA, USA) were used as control calibrators on each plate. The primer sequences for ERCC1, DPD, and ACTB were as previously described (Schneider et al, 2005). The Ct was the fractional cycle number at which the fluorescence generated by cleavage of the probe exceeded a fixed level above baseline. The relative amount of tissue target mRNA standardised against the amount of $A C T B$ mRNA was expressed as follows: $-\triangle \mathrm{Ct}=$ - $\left(\mathrm{Ct}_{(\text {target gene-1) }}-\mathrm{Ct}_{(\beta \text {-actin })}\right)$. The ratio of the number of target mRNA copies to the number of ACTB mRNA copies was then calculated as follows: $2^{-\Delta \mathrm{Ct}} \times K$. Here, $K$ is a constant (Livak and
Schmittgen, 2001). Contamination with genomic DNA was limited by amplifying nonreverse-transcribed RNA.

\section{Immunohistochemistry}

The FFPE tumour tissues were sliced into $4-\mu \mathrm{m}$ sections. The tissue specimens on the slide were then deparaffinised, and endogenous peroxidase was inactivated. For ERCC1 analysis, the slides were incubated at $4{ }^{\circ} \mathrm{C}$ overnight with the primary anti-ERCC1 monoclonal antibody (Clone D-10; Santa Cruz Biotechnology, Inc., Santa Cruz, CA, USA) in a dilution of $1: 100$. For DPD analysis, the slides were incubated at $4{ }^{\circ} \mathrm{C}$ overnight with the primary anti-DPD monoclonal antibody (Clone OF-303, Taiho Pharmaceutical Co., Ltd, Tokyo, Japan) in a dilution of $1: 100$. They were then reacted with a reagent containing horseradish peroxidase-labelled polymer-bound anti-mouse IgG (EnVision + system; Dako Japan Inc., Tokyo, Japan). The chromogenic substrate used for detection was DAB (3,3'-diaminobenzidine). Slides were counterstained with haematoxylin.

\section{Immunohistochemical data analysis}

The staining intensities of ERCC1 (Kim et al, 2009) and DPD (Okabe et al, 2000) were evaluated on a scale from 0 to $2+$, as described previously with slight modifications. In brief, the positive reaction for both antibodies was scored into three grades, according to the intensity of the staining: $0,1+$, and $2+$. The percentages of ERCC1- and DPD-positive cells were also scored into three categories: $0(0 \%), 1(1-49 \%)$, and $2(50-100 \%)$. The product of the intensity by percentage scores was used as the final score. The immunostained specimens were independently evaluated by two blinded investigators ( $\mathrm{HB}$ and $\mathrm{HO}$ ). There was close agreement $(>90 \%)$ between the two investigators; in the case of any disagreement, final grading was determined by consensus.

\section{Statistical analysis}

Categorical data analysis was conducted using the $\chi^{2}$ test. The $\mathrm{GI}_{50}$ of 5-FU and ERCC1, mRNA level of ERCC1 and DPD, and immunohistochemical score of ERCC-1 and DPD were compared using Spearman's correlation coefficient. Either the Student's $t$-test or Wilcoxon test was performed to determine the differences between groups. Results were considered statistically significant at $P<0.05$. All statistical analyses were done with JMP version 8.01 (SAS Institute Inc., Cary, NC, USA).

\section{RESULTS}

\section{Data mining in the NCI database}

The relationship between the cytotoxic effects of oxaliplatin (NSC266046) and 5-FU (NSC19893) in 60 NCI60 panel cell lines is shown in Figure 1A. The cytotoxic effects of oxaliplatin were significantly correlated with those of 5-FU (Spearman's Rho $=0.55$, $P<0.0001$ ).

For elucidating the underlying mechanism of the correlations between oxaliplatin and 5-FU cytotoxicities, gene expression levels as determined by cDNA microarray analysis were also examined. The NCI60 panel cell lines were arbitrarily classified as oxaliplatinhigh-sensitive and oxaliplatin-low-sensitive cell lines according to their respective $\mathrm{GI}_{50}$ values. The oxaliplatin-high-sensitive cell lines were those with $\mathrm{GI}_{50}$ values within the 15 th percentile, whereas the oxaliplatin-low-sensitive cell lines were above the 85th percentile. The remaining cell lines were classified as having intermediate sensitivity.

The Student's $t$-test revealed that the gene expression level of ERCC1 differed significantly $(P<0.05)$ between oxaliplatin-highsensitive and oxaliplatin-low-sensitive cell lines, as shown in 
A

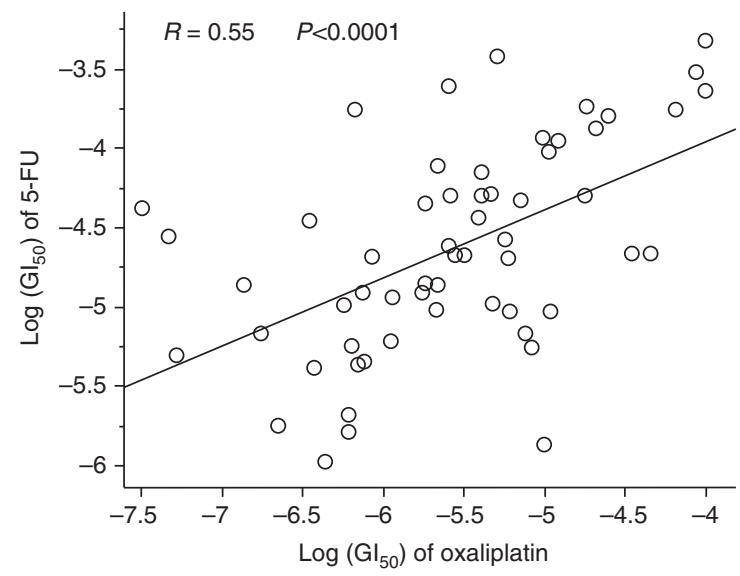

B
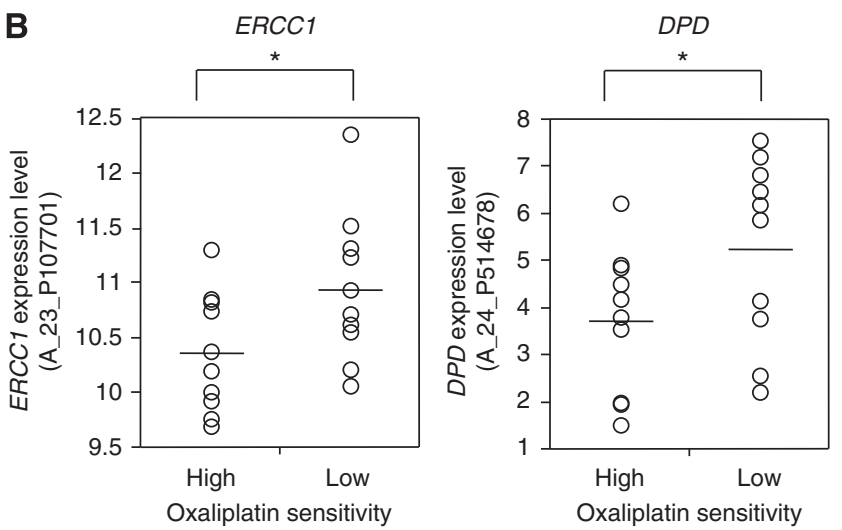

Figure I Oxaliplatin-resistant cells showed high ERCCI and DPD expression in in silico analysis. (A) Relationship between cytotoxic effects of oxaliplatin (NSC266046) and 5-FU (NSC19893) in $60 \mathrm{NCl} 60$ panel cell lines. (B) Comparison of gene expression level, ERCCI and DPD, or copy number between low sensitive cells and high sensitive cells to oxaliplatin. Data expressed as $\log _{2}$ (per chip normalised value $\times 500$ ). ${ }^{*} P<0.05$.

Table I Patient characteristics

\begin{tabular}{|c|c|c|c|}
\hline & $\begin{array}{l}\text { Oxaliplatin } \\
\text { free, } n=21 \\
(\%)\end{array}$ & $\begin{array}{l}\text { Oxaliplatin } \\
\text { treated, } \\
n=24(\%)\end{array}$ & $P$-value ${ }^{a}$ \\
\hline Gender, no. (\%) & & & 0.344 \\
\hline $\begin{array}{l}\text { Male } \\
\text { Female }\end{array}$ & $\begin{array}{r}13(62) \\
8(38)\end{array}$ & $\begin{array}{r}18(75) \\
6(25)\end{array}$ & \\
\hline Age & & & 0.715 \\
\hline $\begin{array}{l}\text { Median, years } \\
\text { Range, years }\end{array}$ & 62 & 63 & \\
\hline $\begin{array}{l}\text { Range, years } \\
\text { Tumour location (\%) }\end{array}$ & $45-75$ & 28-82 & 0.974 \\
\hline $\begin{array}{l}\text { Proximal colon } \\
\text { Distal colon } \\
\text { Rectum }\end{array}$ & $\begin{array}{l}3(14) \\
9(43) \\
9(43)\end{array}$ & $\begin{array}{r}3(13) \\
11(46) \\
10(42)\end{array}$ & \\
\hline Differentiation (\%) & & & 0.873 \\
\hline Well & $10(48)$ & $12(50)$ & \\
\hline Prior chemotherapy (\%) & $11(52)$ & $12(30)$ & - \\
\hline $\begin{array}{l}\text { None } \\
5-\mathrm{FU} / \mathrm{LV} \\
\mathrm{SL}+\mathrm{CPT}^{-}-1 /(\mathrm{R} / \mathrm{S})\end{array}$ & $\begin{aligned} 19 & (90) \\
1 & (5) \\
1 & (5)\end{aligned}$ & - & \\
\hline $\begin{array}{l}\text { SI + CPT-II (IRIS) } \\
\text { mFOLFOX6 }\end{array}$ & $\underline{1}$ & $20(83)$ & \\
\hline mFOLFOX 6 + bevacizumab & - & $4(17)$ & \\
\hline
\end{tabular}

Abbreviations: 5-FU/LV = fluorouracil/leucovorin; $\quad I R I S=$ irinotecan and $S-I$; mFOLFOX6 $=$ modified FOLFOX6. ${ }^{a}$ The $P$-values for gender were calculated using $\chi^{2}$ test. The $P$-values for age, tumour location, differentiation, and prior chemotherapy were calculated using the Wilcoxon test.
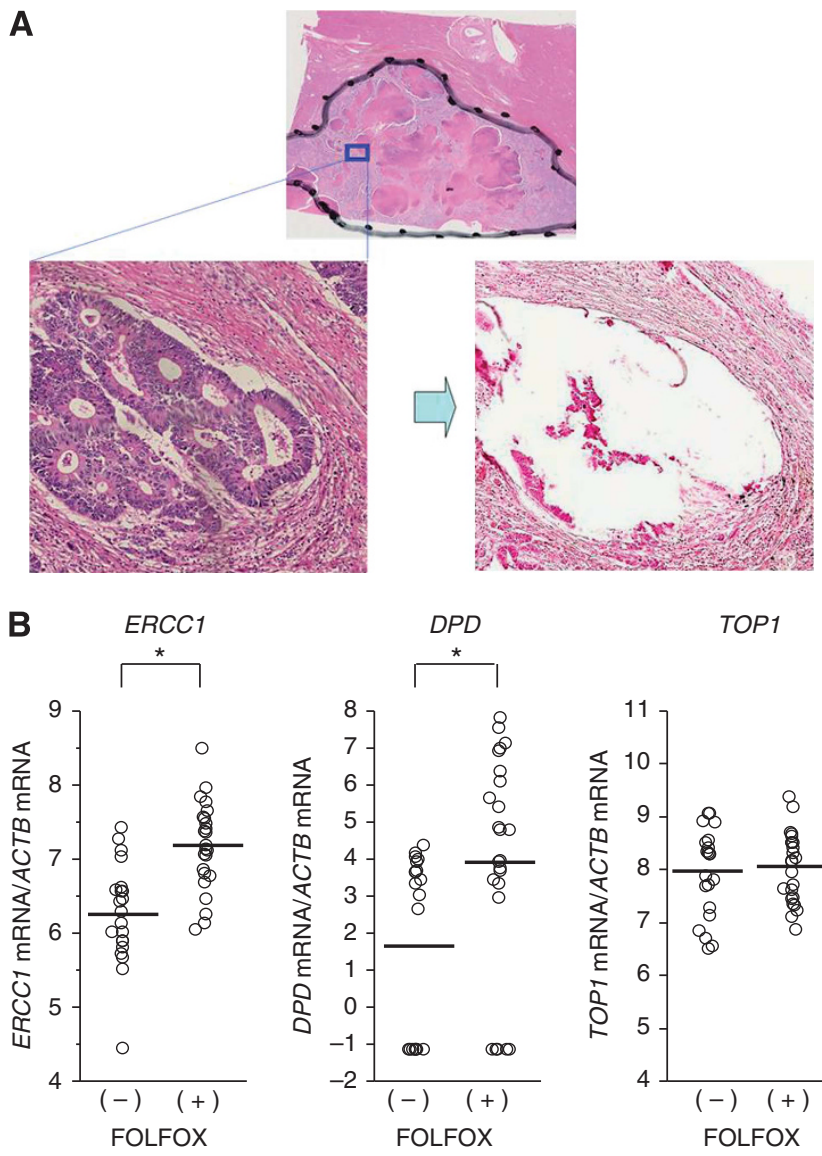

TOP 1

Figure 2 The ERCCI and DPD mRNAs upregulated in CRC patients with preoperative FOLFOX. (A) Typical slide for pathological diagnosis of FFPE tumour specimens (magnification $\times 2.4$ ). Sections, 5- $\mu$ m-thick, stained with haematoxylin and eosin before microdissection (magnification $\times 50)$. After staining with nuclear fast red, standard manual microdissection was performed (magnification $\times 50$ ). (B) Comparison of gene expression levels of ERCCI,DPD, and TOPI in tumour cells with or without FOLFOX regimen before hepatectomy. $* P<0.001$ for $E R C C I$ and $P=0.005$ for DPD, respectively.

Figure 1B. Interestingly, the gene expression level of $D P D$ also differed significantly $(P<0.05)$ between oxaliplatin-high-sensitive and oxaliplatin-low-sensitive cell lines (Figure 1B). Expression levels of ERCC1 and DPD in oxaliplatin-low-sensitive cell lines were 1.5 and 2.9 times higher than those in high-sensitive cell lines, respectively.

Lower sensitivity to oxaliplatin was associated with a parallel increase in ERCC1 and DPD expression. This finding may support that ERCC1 influences cytotoxicity after oxaliplatin treatment. Based on the findings of recent clinical translational studies (Lentz et al, 2005), ERCC1 was likely a predictive marker for colorectal cancer patients receiving oxaliplatin-containing therapy. Therefore, ERCC1 was investigated using clinical specimens from patients who had received a first-line chemotherapy with or without oxaliplatin.

\section{Patient characteristics}

Table 1 summarises patient characteristics. The median patient age at the time of liver dissection was 62 years (range, 28-82 years). There were no significant differences in clinicopathological factors such as gender, age, tumour location, or differentiation between patients with and without a prior oxaliplatin regimen. 


\section{Gene expression level of tumour specimens}

The FFPE tumour specimens resected from liver metastasis were subjected to manual microdissection to ensure that only tumour cells were dissected (Figure 2A). As shown in Figure 2B, ERCC1 and $D P D$, but not $T O P 1$, showed statistically significant higher expression in FOLFOX-treated patients $(n=24)$ compared with the nontreated group $(n=21)$. The mean expression level of ERCC1 and $D P D$ in those receiving the FOLFOX regimen was 1.8 and 4.9 times higher, respectively, than in patients without any prior oxaliplatin-containing chemotherapy (ERCC1, $P<0.0001 ; D P D$, $P=0.005)$. The expression level of ERCC1 was significantly correlated with that of $D P D$ (Spearman's correlation coefficient $=$ $0.519 ; P=0.0003)$.

\section{Immunohistochemical results}

The RT-PCR analysis revealed higher expression of ERCC1 and $D P D$ in FOLFOX-treated patients than nontreated patients. To confirm the protein expression levels of these genes, immunohistochemical examination was performed. The protein expression of ERCC1 (Figures 3A-C) was found in tumour cells, especially in the nucleus, whereas DPD protein expression was found in tumour cells and stromal cells (Figures 3D-F). For ERCC1, the mean (s.d.) expression was $0.48(0.68)$ in patients without FOLFOX and 1.42 (1.41) with FOLFOX (Figure 3G). For DPD, the mean (s.d.) expression was $0.14(0.36)$ in patients without FOLFOX and 0.79 (1.02) with FOLFOX (Figure 3G). In accordance with RT-PCR results, immunohistochemical analysis showed that protein expression of both ERCC1 and DPD was significantly higher in FOLFOX-treated patients than nontreated patients $(P=0.015$ and 0.0025 , respectively; Figure $3 G$ ). Furthermore, a significant correlation between ERCC1 score and DPD score was shown (Spearman's correlation coefficient $=0.65 ; P$-value $<0.0001$ ).

\section{DISCUSSION}

In the present study, gene expression levels of ERCC1, which were extracted by the data mining process of NCI60 screening panel data, were significantly higher in recurrent metastatic cancer cells resected from patients who had received the FOLFOX regimen than from patients with no prior oxaliplatin-containing chemotherapy. In addition, the nucleoside catabolic gene DPD expression level also showed significant differences between patients with and without oxaliplatin as a first-line regimen. Given that the IRIS regimens with the DPD inhibitory fluoropyrimidine may show superior activity against DPD-high tumours compared with FOLFIRI, our
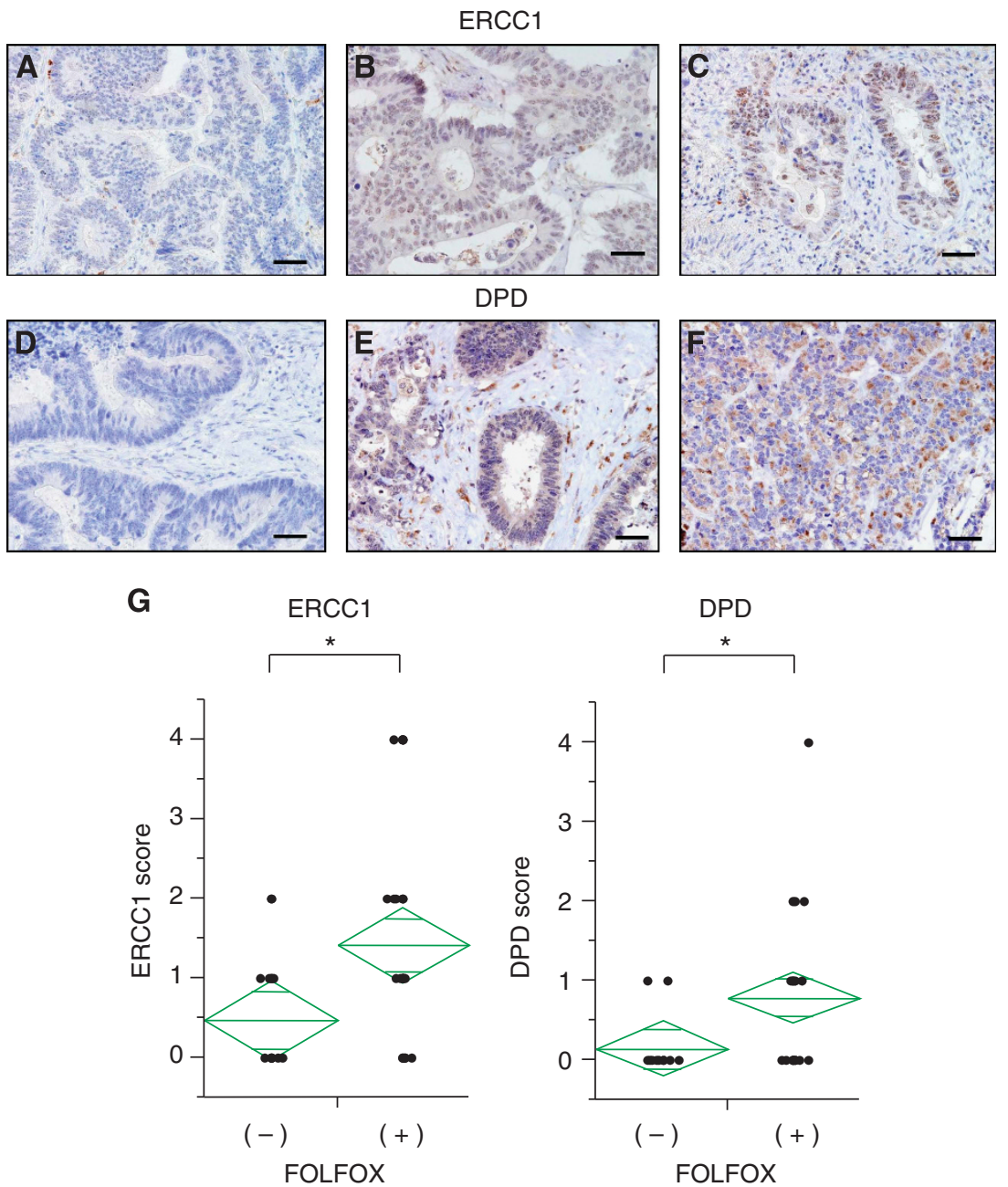

Figure $3 \mathrm{ERCCl}$ and DPD upregulated in CRC patients with preoperative FOLFOX. Representative pictures of ERCCI and DPD in CRC patients. Cases of CRC showing weak $(\mathbf{A})$, moderate $(\mathbf{B})$, and strong $(\mathbf{C})$ ERCCI staining. Cases of CRC showing weak $(\mathbf{D})$, moderate $(\mathbf{E})$, and strong $(\mathbf{F})$ DPD staining; bar $=50 \mu \mathrm{m}$. (G) The expression scores of ERCCI and DPD were compared between patients with FOLFOX and patients without FOLFOX using Wilcoxon test. $* P=0.015$ for $E R C C I$ and $P=0.0025$ for DPD, respectively. 


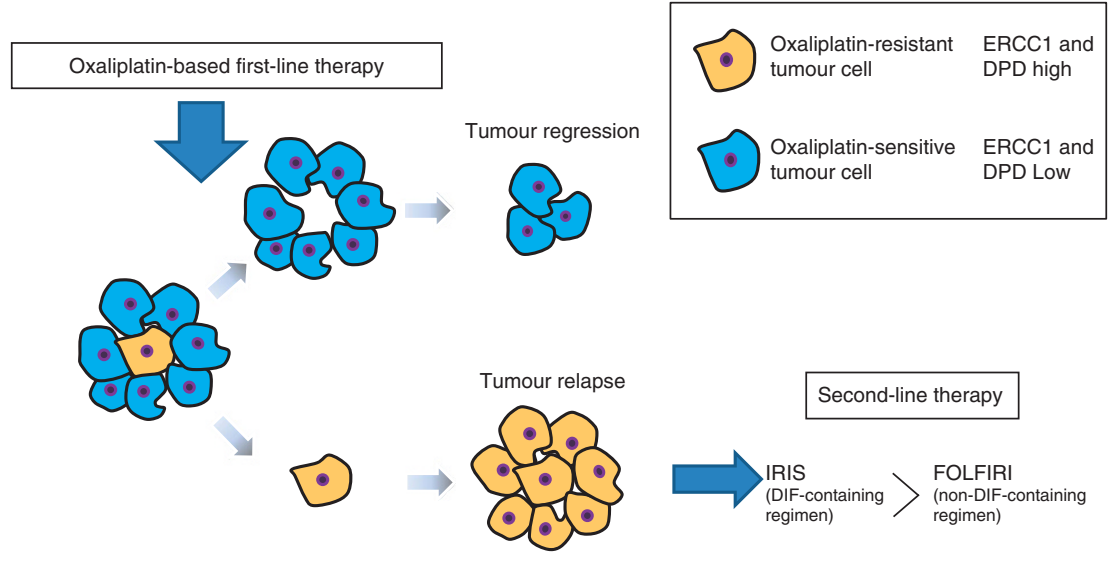

Figure 4 Hypothesis of molecular mechanism of superiority in IRIS group for prior oxaliplatin-treated patients. This study demonstrated that oxaliplatinresistant tumour cells showed high ERCCI and DPD, and thereby seemed to be sensitive to IRIS therapy.

findings may support the recent clinical result on the superiority of IRIS to FOLFIRI in patients previously treated with oxaliplatinbased chemotherapy.

Colon cancer is known to be a relatively heterogeneous tumour, and is characterised by a heterogenic pool of cells with distinct differentiation patterns. As an example, the K-ras mutation was thought to occur during early-stage tumour development; however, a recent study revealed intratumoural heterogeneity of $K$-ras mutations in $35-47 \%$ of primary colorectal carcinomas (Giaretti et al, 1996; Al-Mulla et al, 1998; Losi et al, 2005). Baldus et al (2010) also reported heterogeneity between primary tumours and lymph-node metastases in 31\% (K-ras), 4\% (BRAF), and $13 \%$ (PIK3CA) of cases. Watanabe et al (2011b) found intratumoral heterogeneity of $K$-ras mutations in laser-captured microdissected specimens with respect to discordant $K$-ras status between primary and metastatic colorectal tumours. Such genetic alterations, not only in $\mathrm{K}$-ras but also in other genes, could result in intratumoral heterogeneous gene expression (Watanabe et al, 2011a). Recently, the concept that cancer might arise from a rare population of cells with stem cell-like properties has received support with regard to several solid tumours, including colorectal cancer (Barker et al, 2007; Dalerba et al, 2007; O'Brien et al, 2007; Ricci-Vitiani et al, 2007; Huang et al, 2009; Ricci-Vitiani et al, 2009; van der Flier et al, 2009). Considering the therapeutic implications of cancer stem cells, the failure of current standard therapies to eradicate tumours fully could be explained by assuming that colorectal cancer stem cells are able to survive treatments and achieve only a transitory clinical remission.

Based on our experimental results and knowledge of tumour cell biology, we propose the following hypothesis to explain why the IRIS regimen was superior to the FOLFIRI regimen for colorectal cancer patients who had been treated with oxaliplatin-based regimen. As shown in Figure 4, heterogeneous tumours were exposed to first-line oxaliplatin-containing therapy (mainly the mFOLFOX6 regimen for the FIRIS study, and partly mFOLFOX6 combined with bevacizumab). After the first-line treatment, oxaliplatin-sensitive tumour cells (i.e., ERCC1 low; illustrated in blue in Figure 4) are killed and a small fraction of relatively oxaliplatin-resistant cells (i.e., ERCC1 high; illustrated in yellow in

\section{REFERENCES}

Al-Mulla F, Going JJ, Sowden ET, Winter A, Pickford IR, Birnie GD (1998) Heterogeneity of mutant versus wild-type Ki-ras in primary and metastatic colorectal carcinomas, and association of codon-12 valine with early mortality. J Pathol 185: 130-138
Figure 4) survive, which might include cancer stem cells. In NCI60 cell line data, ERCC1 and DPD gene expression is confounding; surviving cells will exhibit high $D P D$ gene expression. Consequently, failure of first-line treatment might result in the proliferation of oxaliplatin-resistant tumour cells, which exhibit high levels of DPD gene expression. Because the IRIS (S-1/ irinotecan) regimen contains $\mathrm{S} 1$, the $D P D$ inhibitory fluoropyrimidine, it will show superior activity to FOLFIRI (5-FU/LV/ irinotecan, non- $D P D$ inhibitory fluoropyrimidine) against $D P D$ high tumours. This hypothesis was originally proposed when the updated results of the FIRIS study were reported at the 2011 meeting of the American Society of Clinical Oncology (ASCO) (Baba et al, 2011). Molecular mechanisms explaining why ERCC1 and $D P D$ gene expressions seemed to be confounding each other in cancer cells remain unclear. Recently, methylation has been recognised as an epigenetic alteration that leads to gene silencing in human cancer (Estellar, 2003). The role of aberrant methylation of the DPD or ERCC1 promoter as a potential common epigenetic regulatory mechanism in tumour cells remaining after oxaliplatinbased chemotherapy warrants investigation.

A limitation of the present study was the relatively small number of patients included. Nevertheless, the phenomenon identified might be useful in selecting second-line treatments for patients who would benefit the most, and in providing a rationale for selecting therapy. To confirm our hypothesis, the study should be confirmed using an independent cohort of patients. To our knowledge, this is the first report to demonstrate a basic rationale for second-line therapy against the failures of first-line therapy containing oxaliplatin in colorectal cancer patients.

\section{ACKNOWLEDGEMENTS}

Our study was supported by an unrestricted technical assistance from Taiho Pharmaceutical Co., Ltd, Japan. We thank Keisuke Miyake, Naomi Yokoyama, and Yuko Taniguchi for their technical support to this report. We also thank Takashi Kobunai for his helpful advice.
Baba H, Muro K, Yasui H, Shimada Y, Tsuji A (2011) Updated results of the FIRIS study: A phase II/III trial of 5-FU/1-leucovorin/irinotecan (FOLFIRI) versus irinotecan/S-1 (IRIS) as second-line chemotherapy for metastatic colorectal cancer (mCRC). J Clin Oncol 29: 2011 (Suppl; Abstract 3562) 
Baldus SE, Schaefer KL, Engers R, Hartleb D, Stoecklein NH, Gabbert HE (2010) Prevalence and heterogeneity of KRAS, BRAF, and PIK3CA mutations in primary colorectal adenocarcinomas and their corresponding metastases. Clin Cancer Res 16: 790-799

Barker N, van Es JH, Kuipers J, Kujala P, van den Born M, Cozijnsen M, Haegebarth A, Korving J, Begthel H, Peters PJ, Clevers H (2007) Identification of stem cells in small intestine and colon by marker gene Lgr5. Nature 449: 1003-1007

Ceppi P, Volante M, Novello S, Rapa I, Danenberg KD, Danenberg PV, Cambieri A, Selvaggi G, Saviozzi S, Calogero R, Papotti M, Scagliotti GV (2006) ERCC1 and RRM1 gene expressions but not EGFR are predictive of shorter survival in advanced non-small-cell lung cancer treated with cisplatin and gemcitabine. Ann Oncol 17: 1818-1825

Cunningham D, Pyrhonen S, James RD, Punt CJ, Hickish TF, Heikkila R, Johannesen TB, Starkhammar H, Topham CA, Awad L, Jacques C, Herait P (1998) Randomised trial of irinotecan plus supportive care versus supportive care alone after fluorouracil failure for patients with metastatic colorectal cancer. Lancet 352: 1413-1418

Dalerba P, Dylla SJ, Park IK, Liu R, Wang X, Cho RW, Hoey T, Gurney A, Huang EH, Simeone DM, Shelton AA, Parmiani G, Castelli C, Clarke MF (2007) Phenotypic characterization of human colorectal cancer stem cells. Proc Natl Acad Sci USA 104: 10158-10163

Estellar M (2003) Relevance of DNA methylation in the management of cancer. Lancet Oncol 4: 351-358

Giaretti W, Monaco R, Pujic N, Rapallo A, Nigro S, Geido E (1996) Intratumor heterogeneity of K-ras2 mutations in colorectal adenocarcinomas: association with degree of DNA aneuploidy. Am J Pathol 149: 237-245

Huang EH, Hynes MJ, Zhang T, Ginestier C, Dontu G, Appelman H, Fields JZ, Wicha MS, Boman BM (2009) Aldehyde dehydrogenase 1 is a marker for normal and malignant human colonic stem cells (SC) and tracks SC overpopulation during colon tumorigenesis. Cancer Res 69: 3382-3389

Kim JS, Kim MA, Kim TM, Lee SH, Kim DW, Im SA, Kim TY, Kim WH, Yang HK, Heo DS, Bang YJ, Lee KU, Choe KJ, Kim NK (2009) Biomarker analysis in stage III-IV (M0) gastric cancer patients who received curative surgery followed by adjuvant 5-fluorouracil and cisplatin chemotherapy: epidermal growth factor receptor (EGFR) associated with favourable survival. Br J Cancer 100: 732-738

Kuramochi H, Hayashi K, Uchida K, Miyakura S, Shimizu D, Vallbohmer D, Park S, Danenberg KD, Takasaki K, Danenberg PV (2006) Vascular endothelial growth factor messenger RNA expression level is preserved in liver metastases compared with corresponding primary colorectal cancer. Clin Cancer Res 12: 29-33

Lentz F, Tran A, Rey E, Pons G, Treluyer JM (2005) Pharmacogenomics of fluorouracil, irinotecan, and oxaliplatin in hepatic metastases of colorectal cancer: clinical implications. Am J Pharmacogenomics 5: 21-33

Livak KJ, Schmittgen TD (2001) Analysis of relative gene expression data using real-timequantitative PCR and the 2(-Delta Delta C(T)) Method. Methods 25: 402-408

Losi L, Baisse B, Bouzourene H, Benhattar J (2005) Evolution of intratumoral genetic heterogeneity during colorectal cancer progression. Carcinogenesis 26: 916-922

Muro K, Boku N, Shimada Y, Tsuji A, Sameshima S, Baba H, Satoh T, Denda T, Ina K, Nishina T, Yamaguchi K, Takiuchi H, Esaki T, Tokunaga
S, Kuwano H, Komatsu Y, Watanabe M, Hyodo I, Morita S, Sugihara K (2010) Irinotecan plus S-1 (IRIS) versus fluorouracil and folinic acid plus irinotecan (FOLFIRI) as second-line chemotherapy for metastatic colorectal cancer: a randomised phase $2 / 3$ non-inferiority study (FIRIS study).. Lancet Oncol 11: 853-860

O'Brien CA, Pollett A, Gallinger S, Dick JE (2007) A human colon cancer cell capable of initiating tumour growth in immunodeficient mice. Nature 445: 106-110

O'Neil BH, Goldberg RM (2008) Innovations in chemotherapy for metastatic colorectal cancer: an update of recent clinical trials. Oncologist 13: $1074-1083$

Okabe H, Arakawa K, Takechi T, Fukushima M (2000) Expression of recombinant human dihydropyrimidine dehydrogenase and its application to the preparation of anti-DPD antibodies for immunochemical detection. Gan To Kagaku Ryoho 27: 891-898

Ricci-Vitiani L, Fabrizi E, Palio E, De Maria R (2009) Colon cancer stem cells. J Mol Med (Berl) 87: 1097-1104

Ricci-Vitiani L, Lombardi DG, Pilozzi E, Biffoni M, Todaro M, Peschle C, De Maria R (2007) Identification and expansion of human colon-cancerinitiating cells. Nature 445: 111-115

Rougier P, Lepille D, Bennouna J, Marre A, Ducreux M, Mignot L, Hua A, Mery-Mignard D (2002) Antitumour activity of three second-line treatment combinations in patients with metastatic colorectal cancer after optimal 5-FU regimen failure: a randomised, multicentre phase II study. Ann Oncol 13: 1558-1567

Rougier P, Van Cutsem E, Bajetta E, Niederle N, Possinger K, Labianca R, Navarro M, Morant R, Bleiberg H, Wils J, Awad L, Herait P, Jacques C (1998) Randomised trial of irinotecan versus fluorouracil by continuous infusion after fluorouracil failure in patients with metastatic colorectal cancer. Lancet 352: 1407-1412

Schneider S, Uchida K, Brabender J, Baldus SE, Yochim J, Danenberg KD, Salonga D, Chen P, Tsao-Wei D, Groshen S, Hoelscher AH, Schneider PM, Danenberg PV (2005) Downregulation of TS, DPD, ERCC1, GST-Pi, EGFR, and HER2 gene expression after neoadjuvant three-modality treatment in patients with esophageal cancer. J Am Coll Surg 200: $336-344$

Tournigand C, Andre T, Achille E, Lledo G, Flesh M, Mery-Mignard D, Quinaux E, Couteau C, Buyse M, Ganem G, Landi B, Colin P, Louvet C, de Gramont A (2004) FOLFIRI followed by FOLFOX6 or the reverse sequence in advanced colorectal cancer: a randomized GERCOR study. J Clin Oncol 22: 229-237

van der Flier LG, Haegebarth A, Stange DE, van de Wetering $M$, Clevers H (2009) OLFM4 is a robust marker for stem cells in human intestine and marks a subset of colorectal cancer cells. Gastroenterology 137: $15-17$

Watanabe T, Kobunai T, Yamamoto Y, Matsuda K, Ishihara S, Nozawa K, Iinuma $\mathrm{H}$, Ikeuchi $\mathrm{H}$, Eshima $\mathrm{K}$ (2011a) Differential gene expression signatures between colorectal cancers with and without KRAS mutations: crosstalk between the KRAS pathway and other signalling pathways. Eur J Cancer 47: 1946-1954

Watanabe T, Kobunai T, Yamamoto Y, Matsuda K, Ishihara S, Nozawa K, Iinuma $\mathrm{H}$, Shibuya $\mathrm{H}$, Eshima K (2011b) Heterogeneity of KRAS status may explain the subset of discordant KRAS status between primary and metastatic colorectal cancer. Dis Colon Rectum 54: 1170-1178

This work is published under the standard license to publish agreement. After 12 months the work will become freely available and the license terms will switch to a Creative Commons Attribution-NonCommercial-Share Alike 3.0 Unported License. 